\title{
BALANCED DOUBLE AORTIC ARCH IN A CHILD WITH EFFORT DYSPNEA: A CASE REPORT
}

\author{
Hamid Hoseinikhah ${ }^{1}$, Aliasghar Moeinipour ${ }^{1}$, Atefeh Ghorbanzadeh², Hasan Birjandi ${ }^{3}$, Nahid Zirak ${ }^{4}$, Mohammad $^{2}$
} Abbasi Teshnisi ${ }^{5}$

1: M.D., Assistant Professor of Cardiac Surgery, Department of Cardiac Surgery, Atherosclerosis Prevention Research Center, Imam Reza Hospital, Faculty of Medicine, Mashhad University of Medical Sciences, Mashhad, Iran

2: Medical Student, Student Research Committee, Faculty of Medicine, Mashhad University of Medical Sciences, Mashhad, Iran

3: M.D., Assistant Professor of Pediatric Cardiology, Faculty of Medicine, Imam Reza Hospital, Mashhad University of Medical Science, Mashhad, Iran

4: M.D., Associated Professor of Anesthesiology, Facility of Medicine, Mashhad University of Medical Sciences, Mashhad, Iran

5: M.D., Associated Professor of Cardiac Surgery, Department of Cardiac Surgery, Atherosclerosis Prevention Research Center, Imam Reza Hospital, Faculty of Medicine, Mashhad University of Medical Sciences, Mashhad, Iran

\section{TYPE OF ARTICLE: CASE REPORT}

\begin{abstract}
Introduction: Vascular ring is a relatively rare congenital malformation of the aortic arches which causes trachea-esophageal compression. Double aortic arch is the common form of complete vascular rings. This anomaly is usually presented with respiratory symptoms in early infancy.

Case presentation: A 5-year-old boy was referred to our hospital because of frequent episodes of cough and effort dyspnea. The final diagnosis was double aortic arch, and was established after magnetic resonance angiography which showed balanced type double aortic arch that completely encircled the trachea and esophagus.

Conclusion: Double aortic arch is a complete form of vascular ring and it is an important cause of recurrent respiratory symptoms in infants and children. Our report emphasizes the importance of evaluating children with persistent respiratory symptoms for vascular rings. Early diagnosis and appropriate treatment of this anomaly is associated with a good outcome.

KEYWORDS: Vascular ring, Double aortic arch, Cough, Exertional dyspnea
\end{abstract}

\section{INTRODUCTION}

Vascular ring is a relatively rare congenital malformation of the aortic arch that its branches completely or partially encircle and compress the trachea or esophagus, or both (1-3). The high numbers of these are double aortic arches (DAA), which it is the result of the persistence of both right and left fourth aortic arches. The ascending aorta divides into two arches which pass on both sides of the trachea and esophagus, joining the descending aorta, producing a true ring. The trachea and esophagus are completely encircled and sometimes compressed by the two arches. This anomaly is usually diagnosed during infancy due to symptoms such as dyspnea, stridor, cough, wheezing, recurrent respiratory tract infections or dysphagia $(2,3)$. The right (posterior) arch gives origin to the right carotid and subclavian arteries. The left carotid and subclavian arteries arise from the usually smaller left (anterior) arch. In the majority of patients, right-sided arch is dominant (4).This is a report of a double aortic arch with balanced aortic arches, presenting with effort dyspnea.

\section{Correspondence:}

Associated Professor Dr. Mohammad Abbasi Teshnisi, Department of Cardiac Surgery, Imam Reza Hospital, Mashhad University of Medical Sciences, Mashhad, Iran, Tel: +98.5138022318, Fax: +98.5138525307, E-mail: AbbasiM@mums.ac.ir Received: July 13, 2016, Accepted: August 6, 2016, Published: September 2016 iThenticate screening: July 17, 2016, English editing: August 12, 2016, Quality control: August 24, 2016 (C) 2016 The Authors. This is an open access article under the terms of the Creative Commons Attribution-NonCommercialNoDerivs License, which permits use and distribution in any medium, provided the original work is properly cited, the use is non-commercial and no modifications or adaptations are made. 


\section{CASE PRESENTATION}

\subsection{Patient Characteristics}

A 5-year-old boy was referred to our hospital to diagnostic work-up because of frequent episodes of cough and effort dyspnea. He had history of dyspnea, cough and snoring since birth and was diagnosed with asthma or common cold which was not relieved of the symptoms by routine treatment.

\subsection{Clinical Findings}

Physical examination and laboratory findings were unremarkable. His body weight was $19 \mathrm{~kg}$. Pediatric cardiologist examined and further evaluated him. Chest x-ray was normal. Echocardiography demonstrated good left ventricular ejection fraction $(\mathrm{LVEF}=60 \%$ ), normal pulmonary artery pressure (PAP) and also no intra cardiac defect was found and also, he was initially suspected with aberrant right subclavian artery or other vascular ring anomaly.

\subsection{Diagnostic Focus and Assessment}

The patient was further evaluated with magnetic resonance angiography (MRA) which revealed DAA surrounding the trachea and esophagus with equal arches and separate subclavian and common carotid arteries originated from each arch, furthermore, the descending thoracic aorta was located on the left side (Figure 1).

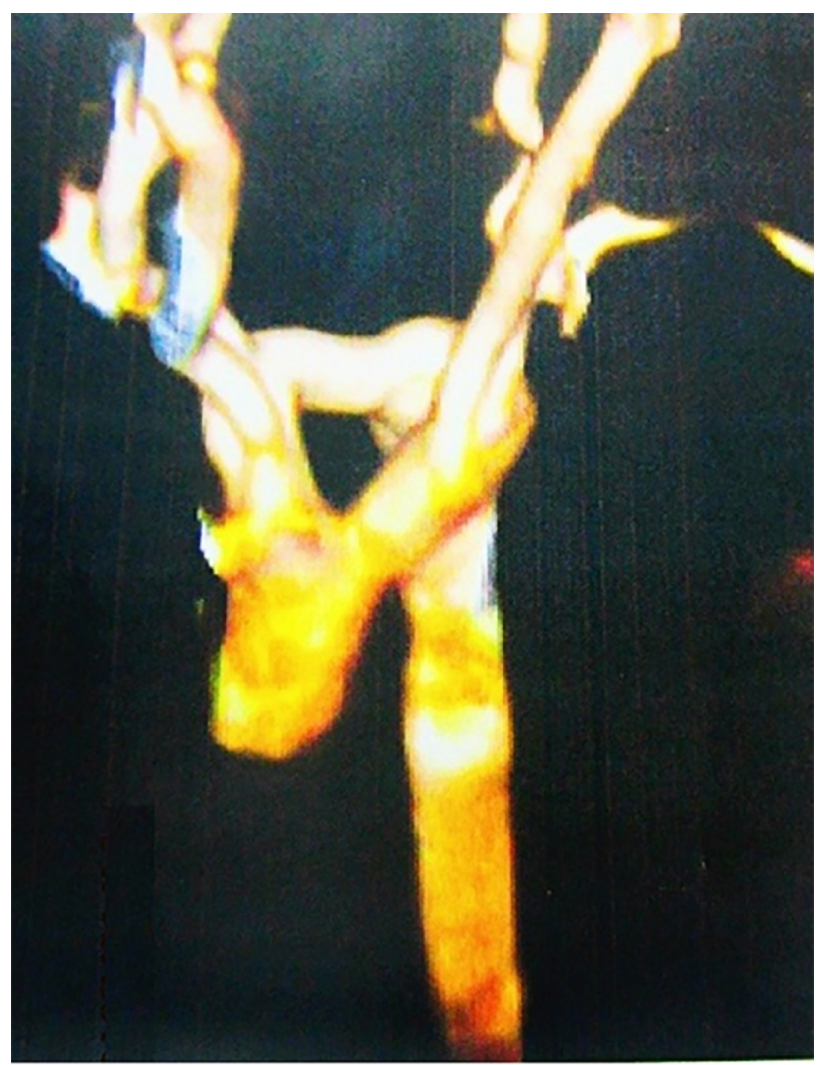

Figure 1. Reconstructed images of magnetic resonance angiography showed balanced type double aortic arch

\subsection{Therapeutic Focus and Assessment}

The patient was scheduled for surgery. A left poster lateral thoracotomy was performed. The left side arch was divided between vascular clamps and both ends were sutured (Figure 2). The child was successfully extubated four hours after surgery and recovery was uneventful.

\subsection{Follow-up and Outcomes}

During the follow-up period, he was discharged from hospital on the third postoperative day and followed up for six months with clinical examination and echocardiography that was in normal condition without any previous symptoms. 


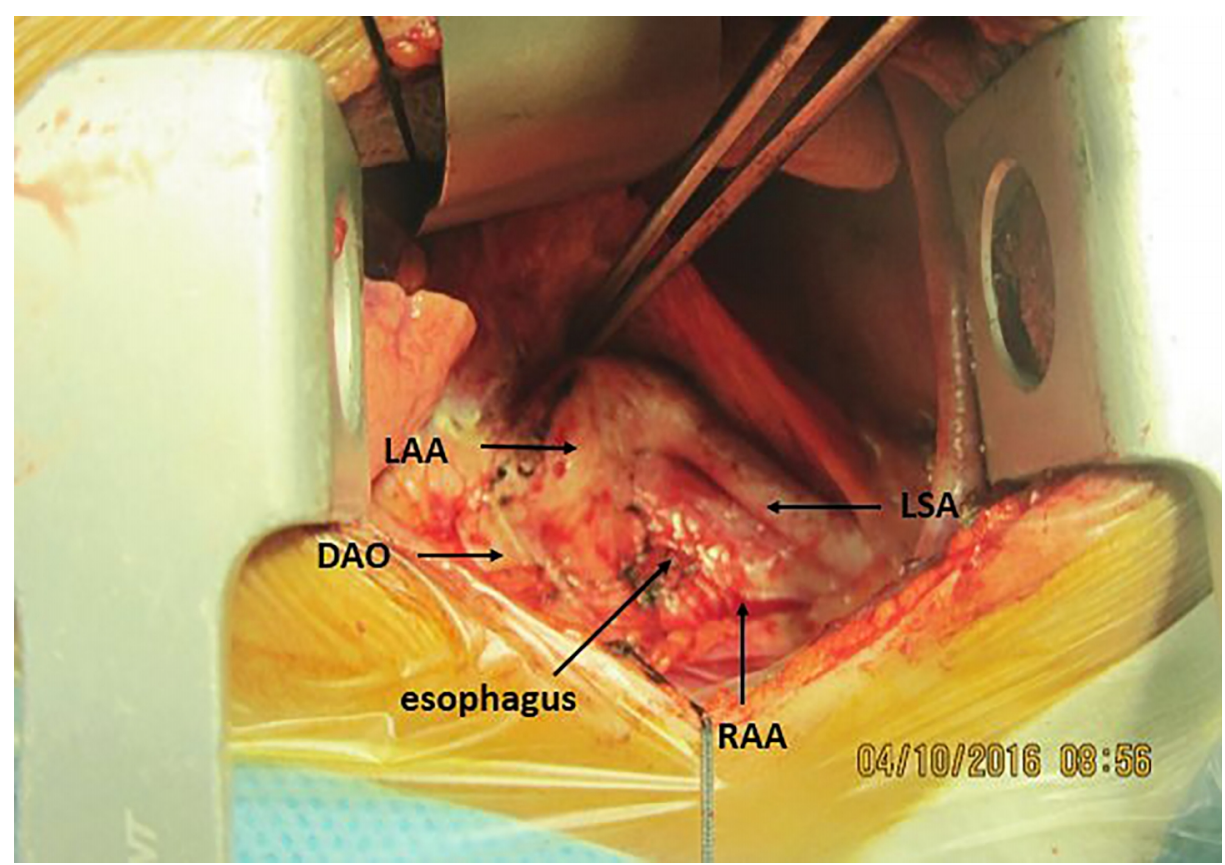

Figure 2. Intra-operative view of the balanced double aortic arch. LAA= left aortic arch. RAA= right aortic arch. $\mathrm{LSA}=$ left subclavian artery. $\mathrm{DAO}=$ descending aorta.

\section{DISCUSSION}

Double aortic arch of aortic arch origin is a rare congenital anomaly which accounts for less than $1 \%$ of all congenital heart diseases $(2,4)$. In cases of DAA, the ascending aorta arises normally, as it leaves the pericardium then it divides into two arches which pass to the left and right of the trachea and esophagus and join posteriorly to the descending aorta (5). Both aortic arches are not usually the same in size or location. In most cases of DAA, the right aortic arch $(75 \%)$ is larger than the left, which often becomes degenerated and atretic or remains as a fibrous band and in $5 \%$, the arches are equal $(1,2)$. The associated cardiac anomalies are uncommon and may be found in about $20 \%$ of DAA patients, but when present, the most common associated cardiac defects include tetralogy of Fallot and transposition of great arteries $(4,6)$. In our case, the patient had a balanced type of DAA which the descending aorta located on the left side and also, he did not have any intra cardiac defects. Of 111 patients with congenital vascular ring reported by Hartyhnszky and colleagues over a period of 13 years, 44 patients fit into the categories of double aortic arch, of which the right aortic arch was dominant in 41 cases, the left in 3 cases but there was not any balanced type of DAA. The descending thoracic aorta was placed on the left side in 11 cases (7). When a DAA is developed, the embryonic fourth aortic arches and dorsal aortic roots persist on both sides. In 1939, Wolman first described the clinical syndrome of trachea and esophagus compression due to DAA (6, 8). In most children, the vascular rings mainly appear early in infancy. The symptoms typically consist of snoring, dyspnea, cough, apnea and cyanosis, recurrent respiratory infections, and dysphagia. Older children may present with gastrointestinal symptoms such as dysphagia, slow feeding and vomiting caused by esophageal compression (2, 4, 9). Kondo and colleagues reviewed 15 adult cases of DAA which required surgery. Thirteen patients were symptomatic, which the most common symptom was dysphagia (66.7\%), and respiratory symptom was less predominant, occurring in 40\% (10). Our patient who was a 5-year-old boy, experienced persistent cough and exertional dyspnea because of trachea compression. Diagnostic procedures that can be used for vascular ring include chest radiography, barium esophagography, echocardiography, CT, MRI, endoscopy, or angiography. Some studies report that $\mathrm{CT}$ or magnetic resonance imaging (MRI) has become the standard modality and choice for delineating detail of vascular ring (11). The MRA imaging of our patient confirmed the diagnosis and showed balanced type DAA and also the descending thoracic aorta located on the left side. Surgery is indicated in all symptomatic patients. Early operation is recommended to prevent serious complications such as hypoxic, apneic spells or further tracheobronchial damage. The surgical procedure of DAA is usually performed via a left thoracotomy approach. The surgical repair includes dividing the small aortic arch and also ligation and division of the ligamentum arteriosus (5). Results after repair of DAA are excellent. In the series reported by Alsenaidi and colleagues (6), there were two fatalities following surgical repair with no late fatalities among 79 patients. Only 1 patient required reoperation for symptoms arising respiratory distress and severe stridor. In our patient, the symptoms improved after surgery. 
Residual respiratory symptoms after surgery are common (up to 54\%) and resolution of symptoms may take up to a year (12).

\section{CONCLUSION}

Double aortic arch is a complete form of vascular ring and it is an important cause of recurrent respiratory symptoms in infants and children. Our report emphasizes the importance of evaluating children with persistent respiratory symptoms for vascular rings. Early diagnosis and appropriate treatment of the patients is associated with a good outcome.

\section{ACKNOWLEDGMENTS:}

We would like to thank Mr. Saeed Hafez Sherbaf and Mohammad Roohi Golkhatmi for their cooperation in this work.

\section{CONFLICT OF INTEREST:}

There is no conflict of interest to be declared.

\section{AUTHORS' CONTRIBUTIONS:}

All authors contributed to this article equally. All authors read and approved the final manuscript.

\section{REFERENCES:}

1) Humphrey C, Duncan K, Fletcher S. Decade of experience with vascular rings at a single institution. Pediatrics. 2006; 117(5):e903-8. PMid: 16585275. doi: 10.1542/peds.2005-1674.

2) Rahayuningsih SE, Kuswiyanto RB, Haryanti M, Phangkawira E. Double Aortic Arch in Adolescence: A Case Report. Open Journal of Pediatrics. 2015; 5(02): 99. doi: 10.4236/ojped.2015.52015.

3) Uchida DA. Late presentation of double aortic arch in school-age children presumed to have asthma: the benefits of spirometry and examination of the flow-volume curve. Respiratory Care. 2009; 54(10): 1402-4. PMid: 19796421.

4) Seo HS, Park YH, Lee JH, Hur SC, Ko YJ, Park SY, et al. A case of balanced type double aortic arch diagnosed incidentally by transthoracic echocardiography in an asymptomatic adult patient. Journal of Cardiovascular Ultrasound. 2011; 19(3): 163-6. doi: 10.4250/jcu.2011.19.3.163.

5) Salooja MS, Singla MK, Singla AD, Bassi AK. Double Aortic Arch Repair: An Interesting Case Scenerio. Advances in Life Sciences and Health. 2014; 1(2): 69-74.

6) Alsenaidi K, Gurofsky R, Karamlou T, Williams WG, McCrindle BW. Management and outcomes of double aortic arch in 81 patients. Pediatrics. 2006; 118(5): e1336-e41. PMid: 17000782. doi: 10.1542/peds.2006-1097.

7) Hartyanszky I, Lozsadi K, Marcsek P, Hüttl T, Sapi E, Kovacs A. Congenital vascular rings: surgical management of 111 cases. European Journal of Cardio-thoracic Surgery. 1988; 3(3): 250-4. PMid: 2624789.

8) Wolman IJ. Syndrome of constricting double aortic arch in infancy: report of a case. The Journal of Pediatrics. 1939; 14(4): 527-33. doi:10.1016/S0022-3476(39)80172-X.

9) Ouchi K, Sugawara T, Ono H, Fujiya T, Kamiyama Y, Kakugawa Y, Mikuni J, Yamanami H. Therapeutic significance of palliative operations for gastric cancer for survival and quality of life. Journal of surgical oncology. 1998; 69(1): 41-4. PMid: 9762890.

10) Kondo C, Takabayashi S, Miyake Y, Onoda K, Shimpo H, Yada I. Successful surgical treatment for an adult case of double aortic arch. The Japanese Journal of Thoracic and Cardiovascular Surgery. 2005; 53(4): 223-6. PMid: 15875561. doi: 10.1007/s11748-005-0112-9.

11) Haramati LB, Glickstein JS, Issenberg HJ, Haramati N, Crooke GA. MR imaging and CT of vascular anomalies and connections in patients with congenital heart disease: significance in surgical planning 1. Radiographics. 2002; 22(2): 337-49. PMid: 11896223. doi: 10.1148/radiographics.22.2.g02mr09337.

12) Van Son Ja, Julsrud Pr, Hagler Dj, Sim Ek, Pairolero Pc, Puga Fj, et al. Surgical treatment of vascular rings: the Mayo Clinic experience. Mayo Clinic Proceedings. 1993; 68(11): 1056-63. PMID: 8231269. 